\title{
Numerical Investigation on Flow Pattern of Air-Oil with Different Viscosities Lubrication
}

\author{
Qunfeng Zeng1*, Jinhua Zhang², Jun Hong2, Wenjun $\mathrm{Su}^{2}$ \\ ${ }^{1}$ Key Laboratory of Education Ministry for Modern Design and Rotor-Bearing System and Fuli School of Food Equipment \\ Engineering and Science, Xi'an Jiaotong University, Xi'an, China \\ ${ }^{2}$ State Key Laboratory for Manufacturing Systems Engineering, Xi'an Jiaotong University, Xi'an, China \\ Email: *zengqf1949@gmail.com, 77192912@qq.com
}

How to cite this paper: Zeng, Q.F., Zhang, J.H., Hong, J. and Su, W.J. (2017) Numerical Investigation on Flow Pattern of Air-Oil with Different Viscosities Lubrication. Engineering, 9, 1-13.

http://dx.doi.org/10.4236/eng.2017.91001

Received: November 23, 2016

Accepted: January 8, 2017

Published: January 11, 2017

Copyright (c) 2017 by authors and Scientific Research Publishing Inc. This work is licensed under the Creative Commons Attribution International License (CC BY 4.0).

http://creativecommons.org/licenses/by/4.0/

\section{(c) (i) Open Access}

\begin{abstract}
In the present work, the performance of oil-air two-phase flow under different lubricant oils was investigated. The simulation method was applied to study the influence of the oil viscosity on the flow pattern, velocity distribution and $R e$ number in oil-air lubrication by FLUENT software with VOF model to acquire the working performance of oil-air lubrication for high-speed ball bearing. This method was used to obtain the optimum lubrication conditions of high-speed ball bearing. The optimum operating conditions that produce the optimum flow pattern were provided. The optimum annular flow was obtained by PAO6 oil with the low viscosity. Reynolds number influences the fluid shape and distribution of oil and air in pipe. The annular flow can be formed when Reynolds number is an appropriate value. The velocity distribution of oil-air two-phase flow at outlet was also discussed by different oil viscosities. The simulating results show that due to the effect of the oil viscosity and flow pattern the velocity decreased and expanded gradually close to the pipe wall, and the velocity increased close to the central pipe. The simulation results provide the proposal for the design and operation of oil-air two-phase flow lubrication experiments in the present work. This work provides a useful method in designing oil-air lubrication with the optimum flow pattern and the optimum operating conditions.
\end{abstract}

\section{Keywords}

Oil-Air Lubrication, Flow Pattern, Two-Phase Flow, Annular Flow

\section{Introduction}

High speed machine tool has become the mainstream of metal cutting in machining aerospace parts, dies and moulds for finishing aluminum alloys, titanium 
alloys and hardened steel alloys because high speed machining is a promising technology for drastically increasing productivity and reducing production costs [1]. And the rotational speed of the spindle would increase with the rapid development of high technology. The ball bearing especially $\mathrm{Si}_{3} \mathrm{~N}_{4}$ ball bearing has been widely used to support high speed ceramic rolling contact bearings or super high speed spindles of high-speed machines tool for high speed cutting because silicon nitride bearings could offer significant benefits for the rolling contact fatigue life and the low density of the material greatly reduces the dynamic loading at ball/raceway contacts in very high speed applications such as machine tool spindles [2]. Investigations have shown that silicon nitride may exhibit superlow friction under appropriate oil lubrication [3] [4]. Therefore, applying an appropriate lubricant lubrication for high speed ball bearing system is necessary for seasons such as chip transport or high speed machining tool cooling. Polyalphaoefin (PAO), which is used as high performance base lubricants for industrial applications, is synthetic hydrocarbons with low side branch densities and comparatively short molecular lengths and the superlow friction performance of PAO lubricating silicon nitride demonstrates that the rolling contact friction level of roller bearings can be obtained in sliding contact under a boundary lubrication condition [5]. And the particulate emissions of synthetic oil are 19\% - 24\% lower than those of mineral oils and more environmental savings can be achieved by adopting the use of synthetic oils. With the development of high-speed spindle, many researchers have investigated its lubrication extensively and intensively. Oil-air lubrication has been used widely to high speed machine tool because of its accuracy in oil quantity control and high cooling efficiency, lubricating efficiency, environmental benefits and precise oil quantity control with the highspeed compressed air [6]. For high speed machine tool, oil-air lubrication system is the most appropriate lubrication system, which is minimum-quantity lubrication. However, the viscosity of the oil affects the lubrication behaviors strongly in oil-air lubrication system. The oil viscosity plays an important role in the lubrication performance of high speed roller ball bearing among these friction conditions. The low viscosity of oils may be avoided, since under high loads the loadbearing capacity might no longer be sufficient, which in turn reduces the service life of roller ball bearings. The high viscosity of oils is benefit to increase the sorption capacity and the load bearing capacity by improving the adherence of oil onto the bearing parts (inner race, outer race and roller) surface, however, the temperature rise can be increased for high viscosity oils produces high friction heating and also leads to poor heat dissipation. Therefore, an appropriate oil viscosity may also increase the load bearing capacity and reduce the temperature increase during operation. In brief, the oil viscosity is one of the important parameters in the oil-air lubrication system, which affects flow pattern, oil film distribution, the load distribution, the motion relationship, friction and wear, etc. However, the influence of the oil viscosity on flow pattern in oil-air lubrication has scarcely been investigated so far.

Numerical simulation has been developed widely in an attempt to rationalize 
lubrication optimization, design evaluation and prediction of oil-air lubrication. It is an effective and economical method for analysis of oil-air two-phase flow. Oil-air two-phase flows are encountered in various industries. The requirement for the optimization of the operating conditions and assessment of safety operations leads to the need for the detailed information on the influences of the physical properties of oil on the flow characteristics of oil-air two-phase flow. Our previous work shows that flow pattern of oil-air two-phase flow is affected by the operating parameters such as velocity and lubrication in oil-air lubrication system [7] [8]. Therefore, the emphasis is placed on investigating the influences of the physical properties of oil-air two-phase flow on flow pattern in this work. The flow characteristics such as the oil viscosity and Reynolds number affect flow patterns of oil-air two-phase flow, therefore, it is necessary to know how to realize the flow pattern in the pipe under the given flow conditions. In the present study, the main objective is to obtain and clarify the influences of the oil viscosity and Reynolds number on the characteristics of flow pattern in oil-air two-phase flow and achieve the optimum oil-air lubrication parameter with volume of fluid (VOF) model in FLUENT software. Firstly, the physical model of flow patterns was built. Secondly, the influences of the oil viscosity and Reynolds number on flow pattern, which have never before appeared in open literature, were discussed with the numerical simulation method and presented. Flow pattern of oil-air two-phase flow was simulated. Finally, the influence of the oil viscosity on the velocity distribution of oil-air two-phase flow at outlet was studied.

\section{Numerical Simulation Models}

Computational fluid dynamics (CFD) is applied to simulate the complicated flows, which has grown from a mathematical curiosity to become an essential tool in almost every branch of fluid dynamics [9]. CFD has found widespread applications, particularly in the simulation of complicated flows. Most of CFD results will give an improved performance, better reliability and more confident scale-up. The CFD software package embodies mathematic knowledge and expresses the stated problem in scientific terms. CFD package FLUENT software is selected as the modeling tool because of its ability to handle the fluid flow and the appropriate software simulating and analyzing the fluid flow.

\subsection{Hydrodynamics Modeling}

\section{1) Materials}

Air and poly-alpha-olefin (PAO) oil are used as gas and fluid in oil-air lubrication system, respectively. To ensure the reliability of the mechanical parts used under extreme conditions of high speed, high load and extreme temperature, $\mathrm{PAO}$ oil is chosen as lubrication oil for high speed roller bearings. PAO oil is a hydrocarbon. PAO oil is a type of synthetic lubricant having excellent properties such as low volatility, high thermal stability and viscosity index, excellent hydrolytic stability and compatibility with a variety of base oils, which has been widely used in the engine oil. Table 1 shows the physical properties of air and PAO oil, 
Table 1. The physical properties of PAO oil and air.

\begin{tabular}{ccc}
\hline & Density $\left(\mathrm{kg} / \mathrm{m}^{3}\right)$ & Viscosity $(\mathrm{Pa} \cdot \mathrm{s})$ \\
\hline Air & 1.225 & $1.8 \times 10^{-5}$ \\
PAO2 & 797 & $6.4 \times 10^{-3}$ \\
PAO6 & 827 & $2.6 \times 10^{-2}$ \\
PAO10 & 835 & $5.5 \times 10^{-2}$ \\
PAO25 & 841 & $2.0 \times 10^{-1}$ \\
PAO40 & 850 & $3.4 \times 10^{-1}$ \\
PAO100 & 853 & 1.0 \\
\hline
\end{tabular}

respectively.

\section{2) Physical Model}

The laws of fluid flow are the basis on establishing the fluid movement equations. There are three equations including the control of fluid flow, heat and mass transfer mathematical formulas. The governing equations of oil-air two-phase system were derived from the continuity and momentum equations. Governing equations include mass conservation equation, conservation of momentum equation and energy equation. The governing equations are listed in the following.

a) Mass conservation equation

$$
\frac{\partial \rho}{\partial t}+\frac{\partial(\rho u)}{\partial x}+\frac{\partial(\rho v)}{\partial y}+\frac{\partial(\rho w)}{\partial z}=0
$$

b) Conservation of momentum equation

$$
\begin{aligned}
& \frac{\partial(\rho u)}{\partial t}+\nabla \cdot(\rho u V)=-\frac{\partial p}{\partial x}+\frac{\partial \tau_{x x}}{\partial x}+\frac{\partial \tau_{y x}}{\partial y}+\frac{\partial \tau_{z x}}{\partial z}+\rho f_{x} \\
& \frac{\partial(\rho v)}{\partial t}+\nabla \cdot(\rho v V)=-\frac{\partial p}{d y}+\frac{\partial \tau_{x y}}{\partial x}+\frac{\partial \tau_{y y}}{\partial y}+\frac{\partial \tau_{z y}}{\partial z}+\rho f_{y} \\
& \frac{\partial(\rho w)}{\partial t}+\nabla \cdot(\rho w V)=-\frac{\partial p}{d z}+\frac{\partial \tau_{x z}}{\partial x}+\frac{\partial \tau_{y z}}{\partial y}+\frac{\partial \tau_{z z}}{\partial z}+\rho f_{z}
\end{aligned}
$$

c) Conservation of energy equation

$$
\begin{aligned}
& \frac{\partial}{\partial t}\left[\rho\left(\mathrm{e}+\frac{V^{2}}{2}\right)\right]+\nabla \cdot\left[\rho\left(\mathrm{e}+\frac{V^{2}}{2}\right) V\right] \\
& =\rho \dot{q}+\frac{\partial}{\partial x}\left(k \frac{\partial T}{\partial x}\right)+\frac{\partial}{\partial y}\left(k \frac{\partial T}{\partial y}\right)+\frac{\partial}{\partial z}\left(k \frac{\partial T}{\partial z}\right) \\
& -\frac{\partial(u p)}{\partial x}-\frac{\partial(v p)}{\partial y}-\frac{\partial(w p)}{\partial z}+\frac{\partial\left(u \tau_{x x}\right)}{\partial x}+\frac{\partial\left(u \tau_{y x}\right)}{\partial y}+\frac{\partial\left(u \tau_{z x}\right)}{\partial z} \\
& +\frac{\partial\left(v \tau_{x y}\right)}{\partial x}+\frac{\partial\left(v \tau_{y y}\right)}{\partial y}+\frac{\partial\left(v \tau_{z y}\right)}{\partial z}+\frac{\partial\left(w \tau_{x z}\right)}{\partial x}+\frac{\partial\left(w \tau_{y z}\right)}{\partial y}+\frac{\partial\left(w \tau_{z z}\right)}{\partial z}+\rho f \cdot V
\end{aligned}
$$

where $\rho$ is density, $u, v$ and $w$ are velocities in the directions of $x, y$ and $z$ respectively, $t$ is time, $\nabla$ is arithmetic operators, $V$ is velocity vector and $V=u \mathbf{i}+v \mathbf{j}+w \boldsymbol{k}, p$ is static pressure, $\tau_{i j}$ is the component of $\tau$, which is the 
viscosity stress produced at the surface of micro unit body due to the molecular viscosity, $f_{x}, f_{y}$ and $f_{z}$ is mass force, $e$ is internal energy, $\dot{q}$ is volumetric heating rate per unit mass, and $k$ is thermal conductivity, respectively. Heat transfer between oil and air is negligible, so this law is ignored.

The flow pattern maps are used to predict two-phase flow regimes in horizontal tubes. The horizontal pipe has $500 \mathrm{~mm}$ in length and $10 \mathrm{~mm}$ in diameter. The end of the pipe is the entrance of air and another end is outlet for the mixture phase. The entrance of oil is located the distance of $20 \mathrm{~mm}$ far from the entrance of air and perpetual with the inlet of air. The inlet of oil is $4 \mathrm{~mm}$ in diameter. Three dimensional models were built with the grid generation program. The model is meshed when the physical model is built by the hexahedron grid, as shown in Figure 1. To save time, half of pipe is used due to the symmetric of pipe.

\subsection{Solver}

The solver is the pressure-based solver, which is suitable for low velocity and incompressible flow. The transient state parameter is applied to obtain the flow pattern map in the time option.

\subsection{Two-Phase Flow Model}

VOF (volume of fluid) model is used to analyze oil-air two-phase flow in the horizontal pipe. The flow patterns of oil-air two-phase flow and the physical properties like the viscosity and density of oil and air are identified. For all flow patterns, annular flow is characterized by a thin liquid film covering the wipe wall and a central gas core loaded with smaller droplets [10]. Two-phase flow model can be used if fluids are not dissolved each other [11]. The turbulence model of Reynolds Stress is selected as two-phase flow model in this work. The turbulence model neglects the vortex viscosity of isomorphism and solves Reynolds Stress equations.

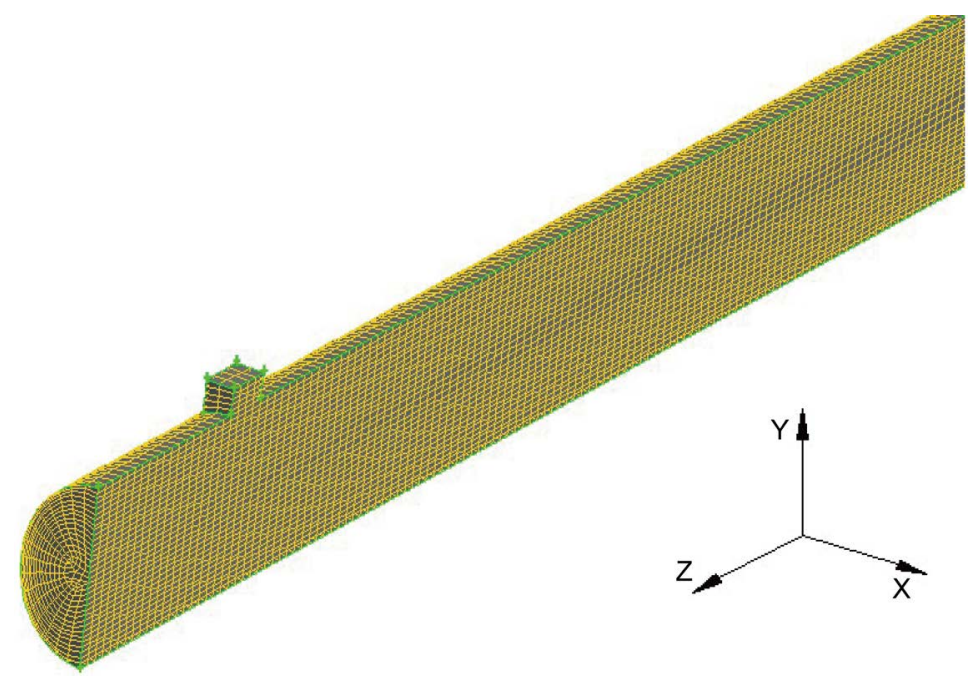

Figure 1. 3-D grid model of the oil pipe. 


\subsection{FLUENT Parameters Setting}

The pressure is atmospheric pressure. Velocity of air and oil at the inlet of pipe is the initial velocity, respectively. Pressure at the outlet of pipe is zero. The turbulence intensity is referred as the ratio of velocity of average flow velocity. The diameter of pipe is the diameter of water power which represents the limit of turbulence flow. The oil viscosity and density of PAO oil are set in the material option in FLUENT software.

\section{Results and Discussion}

The velocity of PAO oil is $10 \mathrm{~m} / \mathrm{s}$ and the velocity of air is $0.05 \mathrm{~m} / \mathrm{s}$ at inlet, respectively.

\subsection{Flow Patterns}

The influence of the oil viscosity on flow pattern of oil-air two-phase flow is investigated by six kinds of PAO oil with different viscosities. Figure 2 shows flow pattern of oil-air two-phase flow under PAO2, PAO6, PAO10, PAO25, PAO40 and PAO100 oils with air lubrication at outlet, respectively. X-axial and Y-axial stand for the length along with the radial direction, respectively. PAO oils are to select and meet the viscosity requirements under oil air lubrication and are classed according to the viscosity of PAO2, PAO6, PAO10, PAO25, PAO40 and $\mathrm{PAO} 100$ at the temperature of $100^{\circ} \mathrm{C}$. It is found from the simulation results that the oil viscosity is very important for the formation of annular flow because PAO100 oil with high viscosity or PAO2 oil with low viscosity cannot be formed the annular flow. The adhesion of oil with low viscosity is poor and the oil flows to the bottom of pipe under gravity condition when the oil enters into the pipe. However, the flowability of oil with high viscosity is poor. The viscosity is high for the large and complex structure of the molecule. It shows that different flow patterns of oil-air two-phase flow are formed under different PAO oils conditions at outlet. The liquid ring protrudes less where the occurrence of the ring film was frequent. The content of PAO oil in two-phase flow at outlet increases with the increase of the oil viscosity. However, it is well known that the optimum annular flow is formed by the least quantity of oil. Therefore, the best annular flow of flow pattern is formed by PAO6 oil with the low viscosity, but it is not lowest viscosity as shown in Figure 3. Under hydrodynamic lubrication conditions, the oil film thickness is dependent on fluid viscosity, surface velocity and load according to the theory of elasto-hydrodynamic lubrication (EHL). The oil film at two relative contact surfaces is formed easily when the viscosity is low under EHL condition [12]. Therefore, the simulation results are agreed with most of other researches. Selecting the correct viscosity of base oil is one of the most critical parameters considered when selecting oil in an application for oil-air lubrication. Once the proper oil viscosity and type have been selected, ensuring the proper level of oil release becomes the limiting factor affecting an oil ability to perform in application. 


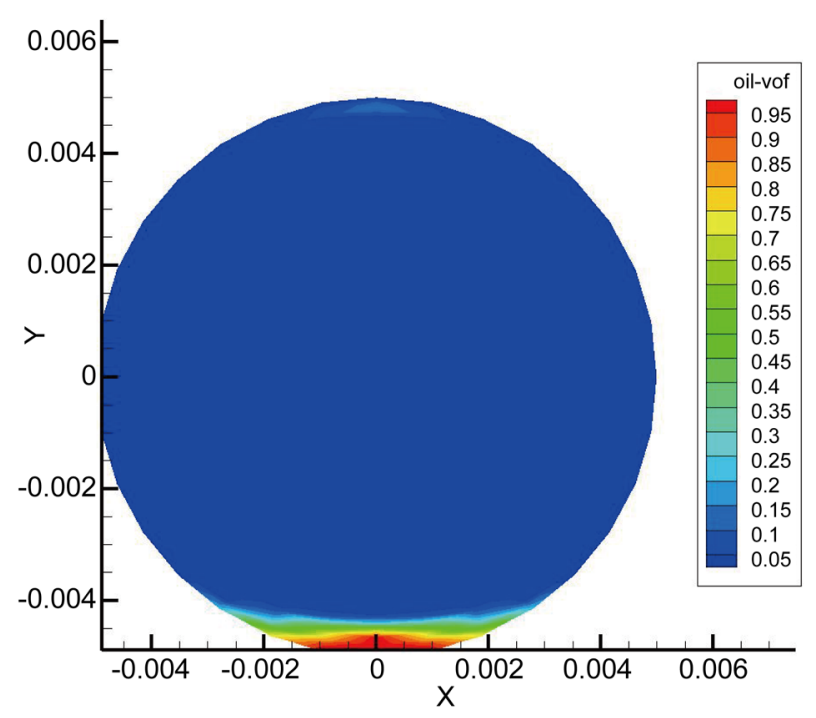

(a)

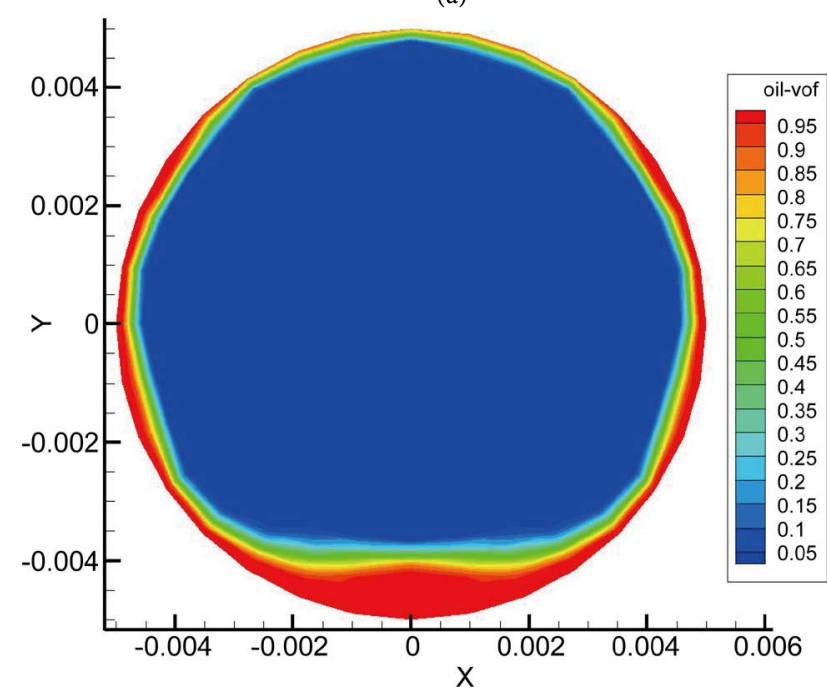

(c)

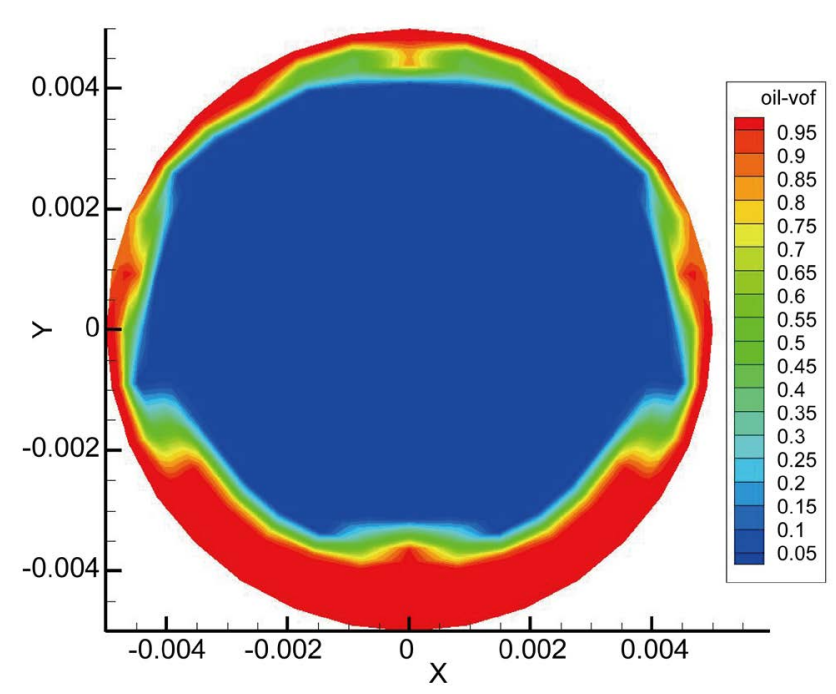

(e)

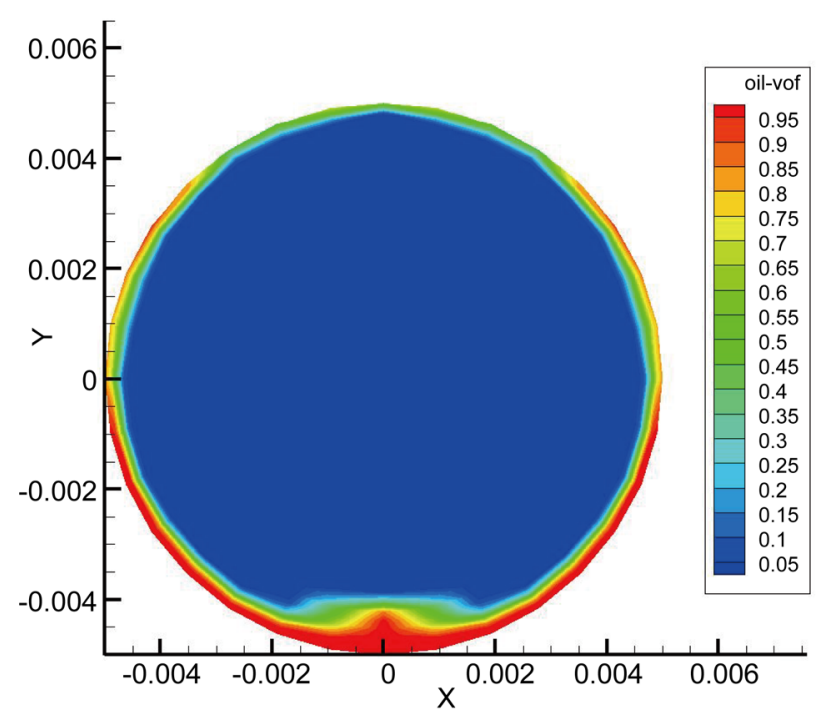

(b)

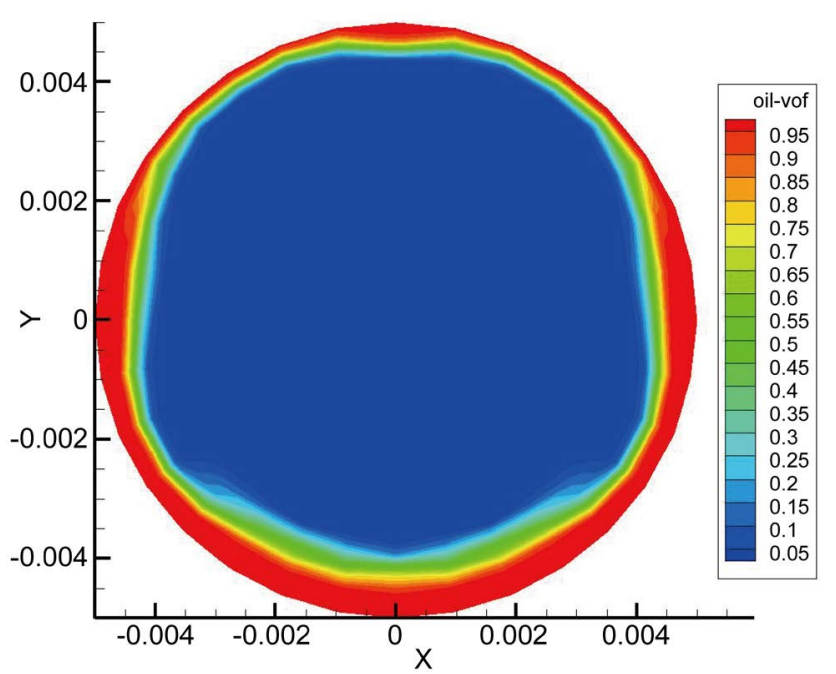

(d)

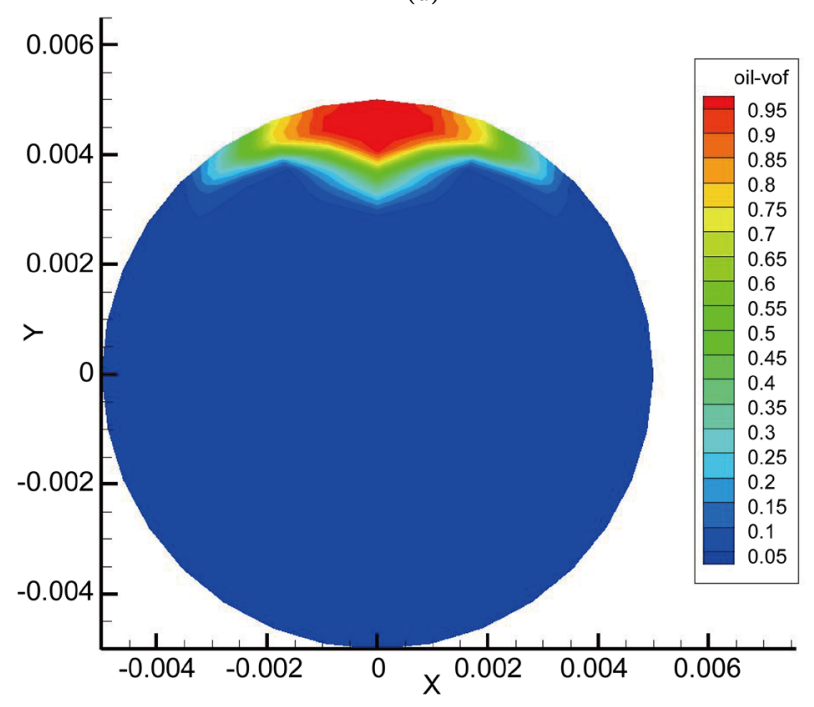

(f)

Figure 2. Flow pattern of oil-air lubrication. (a) PAO2 oil, (b) PAO6 oil, (c) PAO10 oil, (d) PAO25 oil, (e) PAO40 oil, (f) PAO100 oil. 


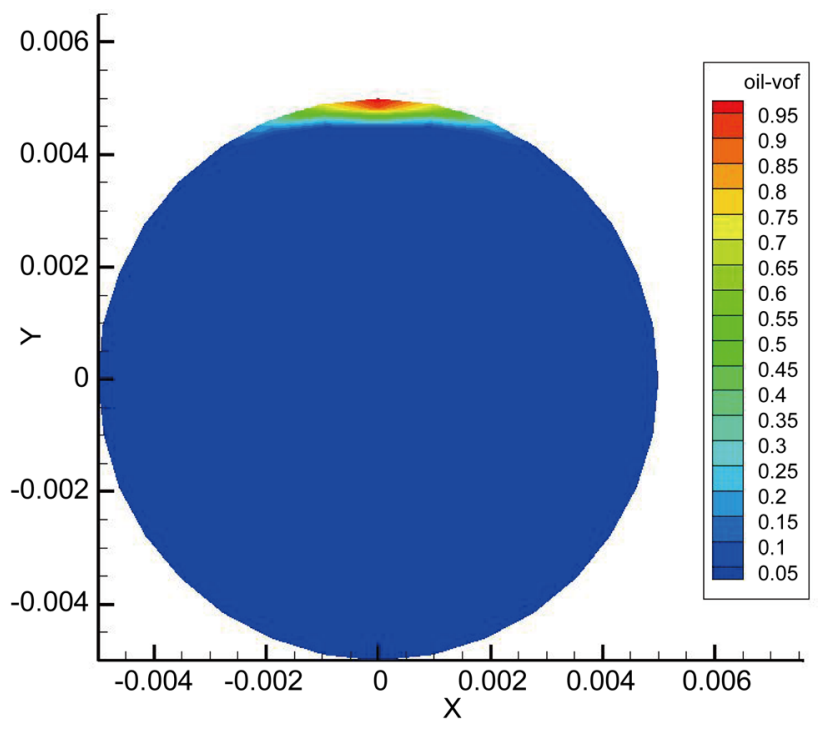

Figure 3. Flow pattern of air and PAO100 oil $(v=100 \mathrm{~m} / \mathrm{s})$.

The annular flow of flow pattern cannot format under $\mathrm{PAO} 2$ oil, and the annular flow of flow pattern form with the increase of the oil viscosity. However, the oil quantity in annular flow becomes large with the increase of the oil viscosity. And the annular flow becomes bad when PAO25 oil is chosen as oil phase. The oil is put on the top of oil wall when PAO100 oil is chosen as oil phase; there is no annular flow at all in the wall. The same phenomena were observed when the velocity of air increase to $100 \mathrm{~m} / \mathrm{s}$, as shown in Figure 4 . There is no annular flow in the oil wall. Only there is smaller quantity of oil on the top of oil wall. The oil with low viscosity is gathering near the lower pipe wall, however, oil with high viscosity is gathering near the upper pipe wall.

The viscosity of the oil affects the lubrication condition. Oils with a low viscosity should be avoided, since at high loads the load-bearing capacity might no longer be sufficient, thereby reducing the service life of the bearings. Grease lubrication and lubrication are both commonly used in rolling bearings. However, when the temperature and operating speed are high, the base oil of the lubricating grease may evaporate and be oxidized, and lubrication performance may deteriorate rapidly. For this condition, the lubrication performance of bearings may be improved by using circular lubrication, atomization lubrication and oil spray lubrication. When operating speed of bearings is very high, bearings must have a sufficient, but not excessive amount of oil to ensure that the bearing is sufficiently lubricated and exorbitant temperature. Oil spray lubrication is an especially effective method in such situations. In oil spray lubrication, oils are injected into bearing from one side of the roller cage shatter. When bearing operates in high speed, the high strength gas flow is formed around the rolling element and the roller cage shatter through which oil is sent to bearings using ordinary lubrication methods. Therefore, oil spray lubrication can be used, and the speed of oil must reach certain value so that it can drill through the hydraulic flow layer under high speed conditions. In this study, the numerical simulation model of the 


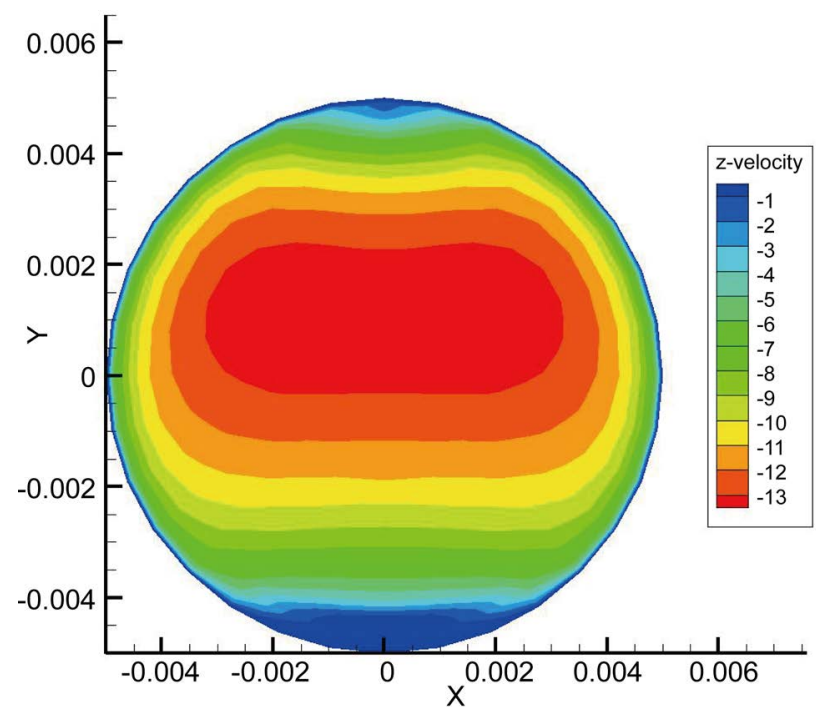

(a)

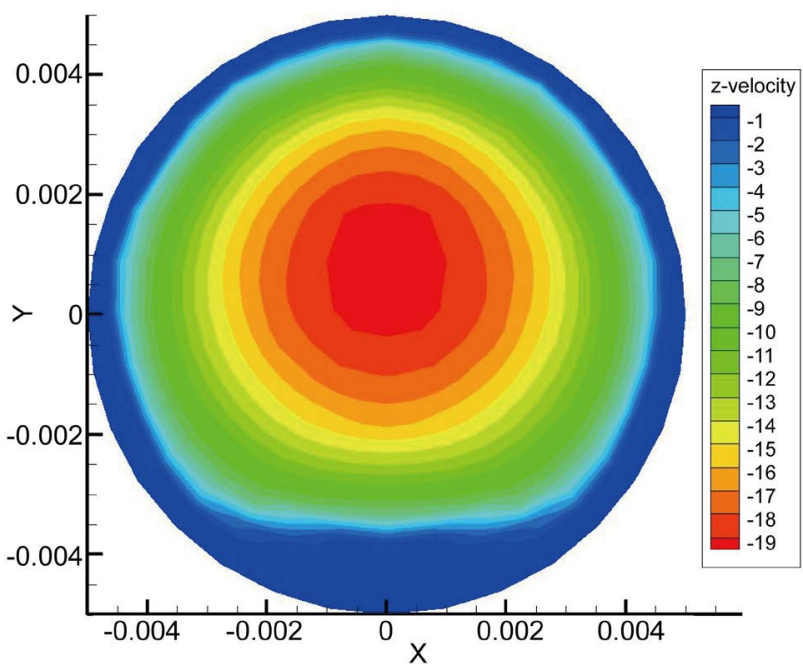

(c)

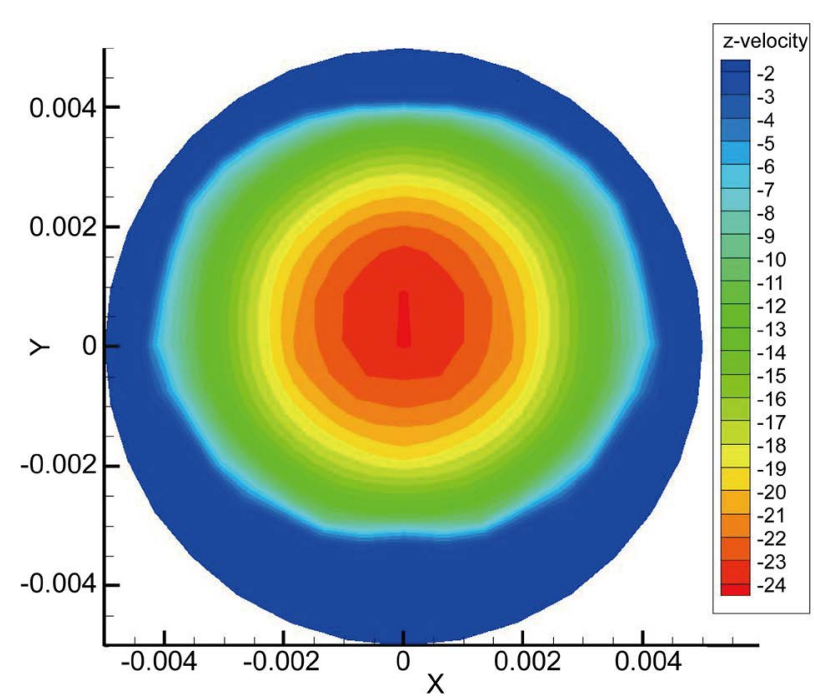

(e)

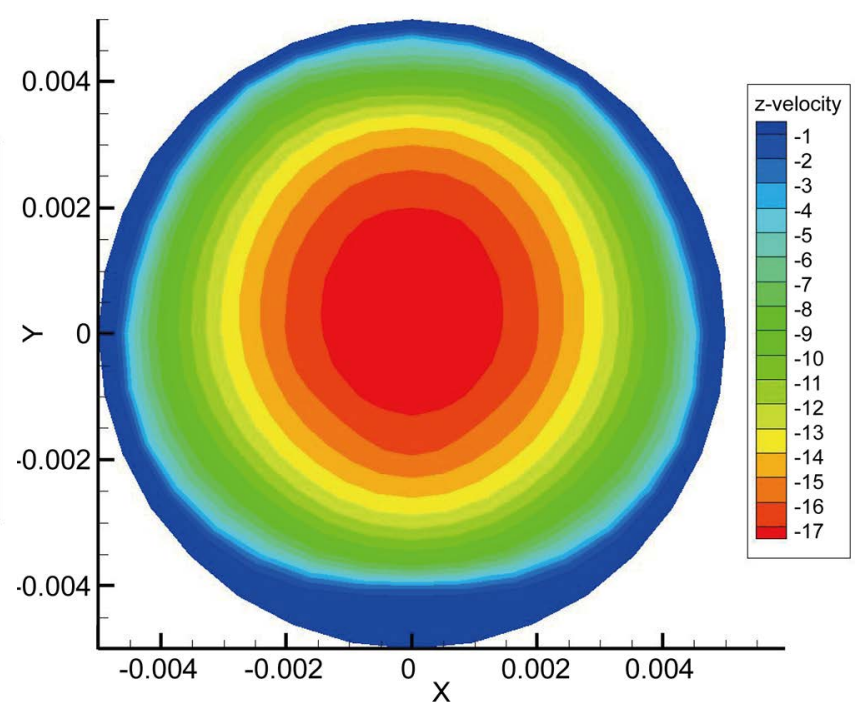

(b)

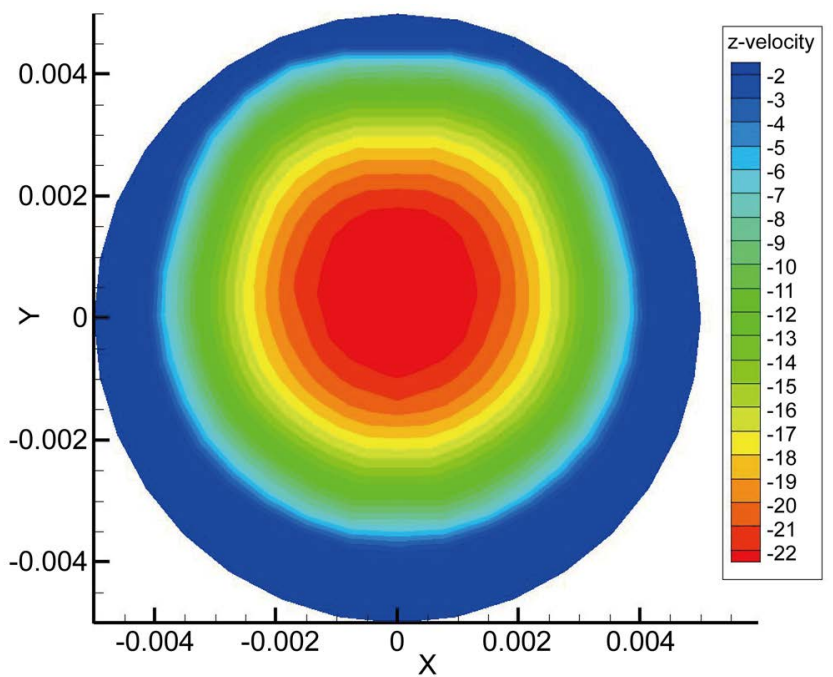

(d)

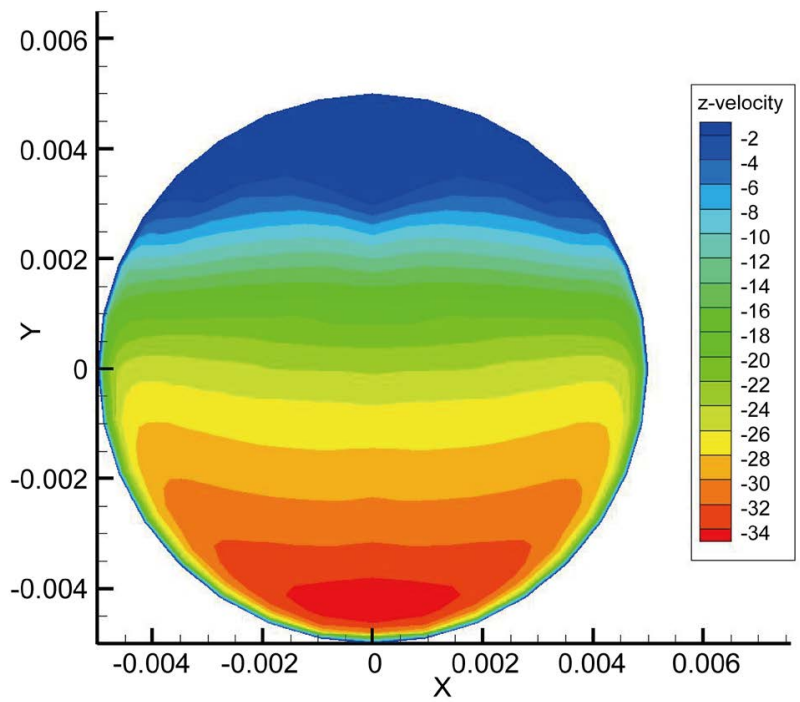

(f)

Figure 4. The velocity distribution pattern of oil-air two phase flow at outlet. (a) PAO2 oil, (b) PAO6 oil, (c) PAO10 oil, (d) PAO25 oil, (e) PAO40 oil, (f) PAO100 oil. 
oil spraying system is established, with spraying speed, spraying angle, oil pressure, oil viscosity, structure of roller cage shatter, rotating speed as the main parameters of the model. By optimization, the best parameters for oil spraying were obtained which can meet lubrication requirement of highs-speed rolling bearing. The velocity increases in the rotational direction, and the maximum value appears at the top of roller. The flow field was influenced mostly by the velocity boundary due to hydrodynamic action of the air flow. The pressure long the diametrical direction decreases with the rotating speed of bearings and the distribution regularity of pressure remains the same. It is concluded from the simulation results that PAO6 oil or other oils with the viscosity close to PAO6 oil are proposed to use the lubricants in oil-air lubrication.

\subsection{Influence of the Oil Viscosity on Velocity Distribution at Outlet}

Figure 4 shows the distribution velocity of PAO2, PAO6, PAO10, PAO25, PAO40, PAO100 oil and air in two-phase flow at outlet, respectively. It is found that the distribution of the oil velocity is affected by the distribution of oil and the oil viscosity influences the distribution of velocity of air and oil phase. It shows that low speed district is near the pipe wall and expands gradually, and the speed increases closely to the central pipe. This tendency becomes obvious with increase of viscosity. The reason is that the viscous resistance of the fluid increases with the oil viscosity increasing, resulting in low speed region expanding. The velocity of oil and air at outlet is much larger than that of PAO oil and air at inlet because the cross-sectional area becomes small where the oil and gas mix. The distribution of the velocity is not uniform even under high speed. Figure 5 shows the distribution velocity pattern of oil (PAO100 oil)-air two phase flow at outlet $(\mathrm{v}=100 \mathrm{~m} / \mathrm{s})$. The effect of velocity magnitude is primarily in the zone of the top wall, which indicates that there are no zones of oil flow; a high-speed zone was formed due to extrusion effects. According to above the analysis about distribution rules of velocity of the oil air two phase flows, it can be seen that the optimal velocity distribution is at the region closer to inner ring of bearings. The diameter of air phase channel decreases with the increase of the oil viscosity since the oil occupies most of pipe. And the velocity of the mixed phase at outlet is higher than that of air or oil phase alone at inlet. The annular flow pattern results in a concentric circular velocity distribution at outlet, which is beneficial to maintain the annular flow.

\subsection{Influence of Reynolds Number on Flow Pattern}

The influence of Reynolds number on flow pattern of oil-air two-phase flow is investigated under different air velocities conditions. In hydromechanics theory, Reynolds number is usually used to characterize the analogy number $(R e)$ about the viscosity effect, as shown in Equation (6).

$$
\operatorname{Re}=\frac{\rho v L}{\mu}
$$




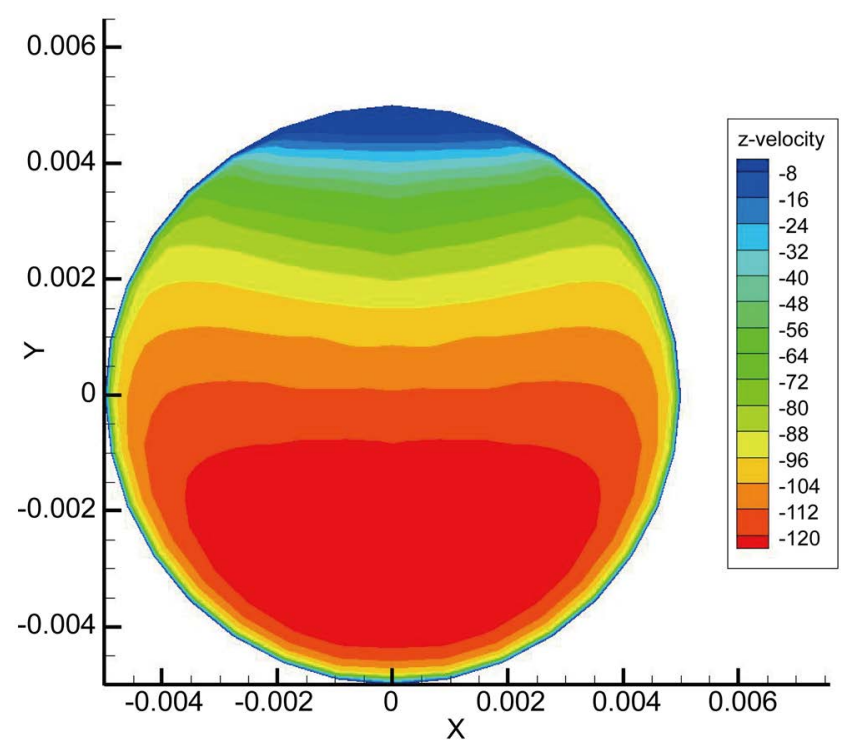

Figure 5. The velocity distribution pattern of oil (PAO100 oil)-air two phase flow at outlet $(v=100 \mathrm{~m} / \mathrm{s})$.

where, $\rho$ is density of fluid, $\mu$ is viscosity of fluid, $v$ is the average velocity of fluid field. $L$, the diameter for the circle pipe, is the characteristic length of fluid field. Flow pattern of oil in two-phase flow depends significantly on Reynolds number of air because the quantity of oil is relatively small in oil-air twophase flow. Reynolds numbers are 685, 6846 and 13691 for $1 \mathrm{~m} / \mathrm{s}, 10 \mathrm{~m} / \mathrm{s}$ and 20 $\mathrm{m} / \mathrm{s}$, respectively. Figure 6 shows the distribution of oil-air flow on the symmetry plane under different Reynolds numbers. It is found that Reynolds number influences the fluid shape of PAO oil strongly. There are large oil drops in oil and most of oil sink at the bottom of pipe at $R e$ of 685. When $R e$ increases to 6846, oil is dispersed uniformly and oil drops become small along with the pipe wall forward. The oil drop is formed into the excellent annular flow at outlet, which meets the requirement of oil-air lubrication. When $R e$ increases to 13,691, oil occurs discontinuity and even there is no oil at the bottom of pipe, so it is not formed into annular flow in two-phase flow. The annular flow can be formed when Reynolds number reaches a critical value. There is no annular flow if Reynolds number is larger than the critical one. It is well known that there is a significant effect of Reynolds number on the log law of mean velocity. And most of the scatter oil is probably the result of oil-air uncertainty involved in measuring turbulence quantities near the pipe wall.

\section{Conclusion}

The influence of the oil viscosity and Reynolds number on flow pattern of air-oil two-phase flow for high-speed rolling bearing is investigated with FLUENT software and the simulation results are presented. The viscosity of PAO oil influences flow pattern of oil-air two-phase flow. The optimum annular flow of flow pattern is obtained by PAO6 oil with the low viscosity. It is concluded that PAO6 oil or other oils with the viscosity close to PAO6 oil are proposed to use 


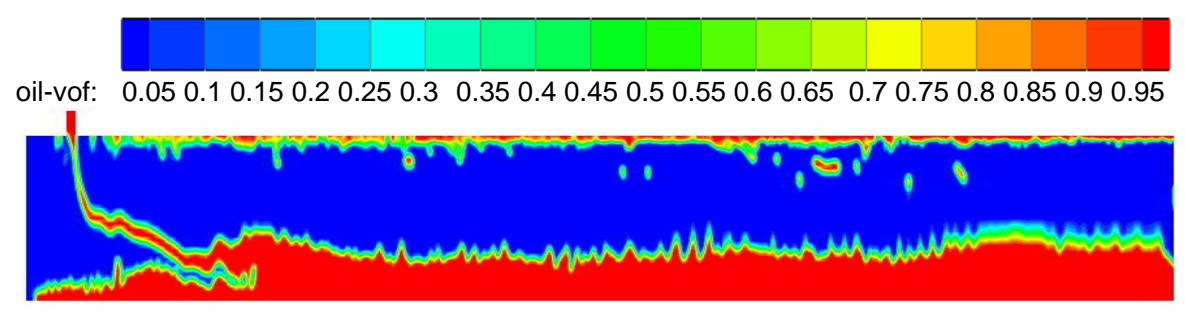

(a)

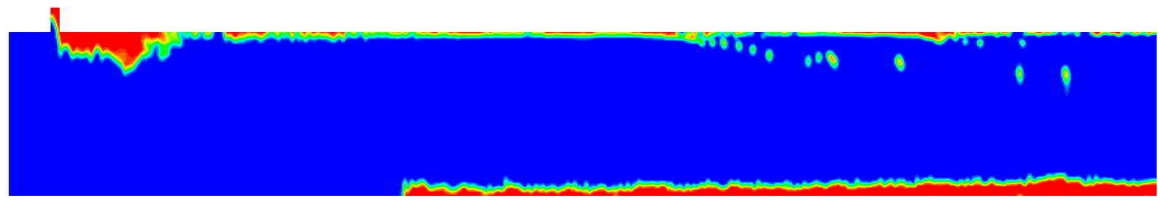

(b)

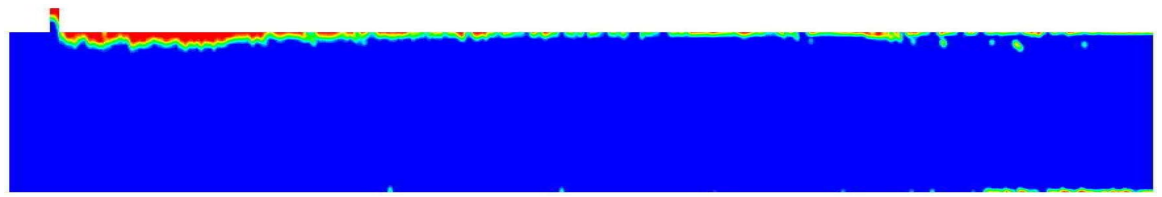

(c)

Figure 6. Distribution of two-phase flow on symmetry plane under different Re numbers: (a) $R e=685\left(u_{\text {air }}=1 \mathrm{~m} / \mathrm{s}\right)$; (b) $R e=6846\left(u_{\text {air }}=10 \mathrm{~m} / \mathrm{s}\right)$; (c) $R e=13691\left(u_{\text {air }}=20 \mathrm{~m} / \mathrm{s}\right)$.

the lubricants in oil-air lubrication. Reynolds number influences the fluid shape and the oil distribution in two-phase flow pipe. The annular flow of flow pattern is formed when Reynolds is appropriate. The velocity of oil and air distributes non-uniformity in oil pipe with different oils and is much larger than that of oil and air at inlet. The annular flow pattern results in a concentric circular velocity distribution at outlet, which is beneficial to maintain the annular flow.

\section{Acknowledgements}

The present work is financially supported by the grant from National Natural Science Foundation of China (No. 51305331, 51675409).

\section{Disclosure Statement}

No potential conflict of interest was reported by the authors.

\section{References}

[1] Lin, C.W., Tu, J.F. and Kamman, J. (2003) An Integrated Thermo-MechanicalDynamic Model to Characterize Motorized Machine Tool Spindles during Very High Speed Rotation. International Journal of Machine Tools and Manufacture, 43, 1035-1050. https://doi.org/10.1016/S0890-6955(03)00091-9

[2] Wang, L.R.W.L., Snidle, R.W. and Gu, L. (2000) Rolling Contact Silicon Nitride Bearing Technology: A Review of Recent Research. Wear, 246, 159-173. https://doi.org/10.1016/S0043-1648(00)00504-4

[3] Zeng, Q., Yu, F. and Dong, G. (2013) Superlubricity Behaviors of $\mathrm{Si}_{3} \mathrm{~N}_{4} / \mathrm{DLC}$ Films under PAO Oil with Nano Boron Nitride Additive Lubrication. Surface and Interface Analysis, 45, 1283-1290. https://doi.org/10.1002/sia.5269 
[4] Sun, L., Zhang, C., Li, J., Liu, Y. and Luo, J. (2013) Superlubricity of $\mathrm{Si}_{3} \mathrm{~N}_{4}$ Sliding against $\mathrm{SiO}_{2}$ under Linear Contact Conditions in Phosphoric Acid Solutions. Science China Technological Sciences, 56, 1678-1684.

https://doi.org/10.1007/s11431-013-5257-7

[5] Erhan, S.Z. and Asadauskas, S. (2000) Lubricant Basestocks from Vegetable Oils. Industrial Crops and Products, 11, 277-282.

https://doi.org/10.1016/S0926-6690(99)00061-8

[6] Jiang, S. and Mao, H. (2011) Investigation of the High Speed Rolling Bearing Temperature Rise with Oil-Air Lubrication. Journal of Tribology, 133, Article ID: 021101. https://doi.org/10.1115/1.4003501

[7] Zeng, Q., Zhang, J., Hong, J. and Liu, C. (2016) A Comparative Study on Simulation and Experiment of Oil-Air Lubrication Unit for High Speed Bearing. Industrial Lubrication and Tribology, 68, 325-335.

[8] Zeng, Q., Zhao, X., Dong, G. and Wu, H. (2012) Study on Lubrication Properties of Nitinol 60 Alloy Used as High-Speed Rolling Bearing and Numerical Simulation of Flow Pattern of Oil-Air Lubrication. Transactions of Nonferrous Metals Society of China, 22, 2431-2438. https://doi.org/10.1016/S1003-6326(11)61481-7

[9] Hirsch, C. (2007) Numerical Computation of Internal and External Flows: The Fundamentals of Computational Fluid Dynamics. Butterworth-Heinemann.

[10] Thomas, B. and Zhang, L. (2001) Mathematical Modeling of Fluid Flow in Continuous Casting. ISIJ International, 41, 1181-1193. https://doi.org/10.2355/isijinternational.41.1181

[11] Stewart, H. and Wendroff, B. (1984) Two-Phase Flow: Models and Methods. Journal of Computational Physics, 56, 363-409. https://doi.org/10.1016/0021-9991(84)90103-7

[12] Zhang, S., Wang, W., Li, X. and Guo, F. (2016) The Effect of Oil Droplet on the Lubrication Performance. Journal of Tribology, 138, 031506-1-9.

https://doi.org/10.1115/1.4032959

\section{Scientific Research Publishing}

Submit or recommend next manuscript to SCIRP and we will provide best service for you:

Accepting pre-submission inquiries through Email, Facebook, LinkedIn, Twitter, etc. A wide selection of journals (inclusive of 9 subjects, more than 200 journals)

Providing 24-hour high-quality service

User-friendly online submission system

Fair and swift peer-review system

Efficient typesetting and proofreading procedure

Display of the result of downloads and visits, as well as the number of cited articles

Maximum dissemination of your research work

Submit your manuscript at: http://papersubmission.scirp.org/

Or contact eng@scirp.org 